\title{
Array CGH Analysis and Developmental Delay: A Diagnostic Tool for Neurologists
}

\author{
F. Cameron, J. Xu, J. Jung, C. Prasad
}

\begin{abstract}
Developmental delay occurs in 1-3\% of the population, with unknown etiology in approximately $50 \%$ of cases. Initial genetic work up for developmental delay previously included chromosome analysis and subtelomeric FISH (fluorescent in situ hybridization). Array Comparative Genomic Hybridization (aCGH) has emerged as a tool to detect genetic copy number changes and uniparental disomy and is the most sensitive test in providing etiological diagnosis in developmental delay. aCGH allows for the provision of prognosis and recurrence risks, improves access to resources, helps limit further investigations and may alter medical management in many cases. aCGH has led to the delineation of novel genetic syndromes associated with developmental delay. An illustrative case of a 31-year-old man with long standing global developmental delay and recently diagnosed 4q21 deletion syndrome with a deletion of $20.8 \mathrm{Mb}$ genomic interval is provided. aCGH is now recommended as a first line test in children and adults with undiagnosed developmental delay and congenital anomalies.
\end{abstract}

RÉSUMÉ: Puce d'hybridation génomique comparative et retard de développement : un outil diagnostic pour les neurologues. Le retard de développement survient chez 1 à $3 \%$ de la population et son étiologie est inconnue chez à peu près $50 \%$ des cas. L'évaluation génétique initiale pour un retard de développement incluait antérieurement une analyse chromosomique et une analyse par FISH (hybridation in situ en fluorescence) de régions subtélomériques. La puce d'hybridation génomique comparative (CGHa) est devenue un outil de détection des changements du nombre de copies géniques ainsi que de la disomie uniparentale et elle est le test le plus sensible pour fournir un diagnostic étiologique dans le retard de développement. Le CGHa permet d'offrir un pronostic et un risque de récurrence, améliore l'accès aux ressources, aide à limiter les évaluations et peut modifier le traitement médical dans bien des cas. Le CGHa a mené à la définition de nouveaux syndromes génétiques associés à un retard de développement. À titre d'exemple, nous décrivons le cas d'un homme âgé de 31 ans qui présentait un retard de développement global depuis longtemps et chez qui un syndrome associé à une délétion 4q21 a été diagnostiqué récemment, soit une délétion de 20,8 Mb. Le CGHa est maintenant recommandé comme test de première ligne chez les enfants et les adultes présentant un retard de développement et des anomalies congénitales.

Can J Neurol Sci. 2013; 40: 777-782

\section{Developmental Delay and Etiological Diagnosis}

Global Developmental Delay (GDD) is a condition in which etiology is known only in 40 to $60 \%$ of cases ${ }^{1}$. The families face considerable challenges in managing adult patients with cognitive delay who have no underlying diagnosis. Etiological diagnosis helps with providing recurrence risk and prognostic information, and avoids further unnecessary invasive investigations. Knowing the underlying basis also helps in providing anticipatory guidelines for proper management, and allows for the family to access community supports ${ }^{2}$. Clinical dysmorphology skills of the physician as well as laboratory and cytogenetic testing have been the mainstay of diagnosis for many decades. Previous recommendations stated that testing should consist of at least a G-banding karyotype and fragile X testing in both genders ${ }^{1}$. Metabolic testing and neurologic imaging are also now included if suggestive findings were present on history and examination. In undiagnosed GDD, the etiological yield of a dysmorphologist and neurologist exams have been noted to be $39-81 \%$ and $42 \%$, respectively ${ }^{3}$. Previous studies on the detection rate of routine cytogenetic testing in the undiagnosed found chromosomal abnormalities in 2.93-11.6\% ${ }^{9}$ with an overall yield of $3.7 \%$ in individuals with undiagnosed $\mathrm{GDD}^{10}$.

\section{Traditional Cytogenetic Investigations}

The classic cytogenetic test is by G-banding analysis ${ }^{11}$. It has been especially useful in detection of aneuploidy (abnormalities in chromosome number) and large structural chromosomal abnormalities such as deletions, duplications, and unbalanced chromosomal rearrangements. With improved technology, it is sensitive for changes between 3 and $5 \mathrm{Mb}$ (mega bases) in size. Many smaller genetic changes, however, cannot be detected by traditional karyotyping.

The development of fluorescent in situ hybridization (FISH) technology allows for detection of smaller chromosomal imbalances. Fluorescent in situ hybridization uses fluorescent probes to hybridize to the complementary DNA sequences. With the selection of an appropriate probe, the presence of certain deletions at loci could be detected with a sensitivity of $\sim 100 \mathrm{~kb}$.

From Western University (FC, JJ, CP), Cytogenetics (JX), Paediatrics (JJ, CP),

Children's Health Research Institute (CP), London Health Sciences Centre and Western University Ontario, London, Ontario; Cytogenetics (JX), Alberta Genetics Services,

Alberta Health Services, Edmonton, Alberta, Canada.

Received January 9, 2013. Final Revisions Submitted July 8, 2013.

Correspondence to: Chitra Prasad, Genetics, Metabolism and Paediatrics, 800

Commissioners Road East, London, Ontario, N6C 2V5, Canada.

Email: Chitra.Prasad@1hsc.on.ca. 
It has been especially useful for diagnosis of many contiguous gene deletion syndromes such as $22 \mathrm{q}$ deletion and Williams syndrome ${ }^{12}$. Subtelomeric deletions have also been recognized as an important cause of developmental delay in 7$8 \%$ of individuals with developmental delay ${ }^{13}$. Fluorescent in situ hybridization, however, cannot tell the size of a deletion or duplication or molecular breakpoints involved ${ }^{14}$. Fluorescent in situ hybridization is not suited to whole genome screening.

\section{Evolution of CGH and aCGH}

In the early 1990's comparative genomic hybridization (CGH) was developed. This involved the co-hybridization of test and reference DNA that had been "differentially labeled" with fluorescent probes $^{15}$, and allowed for whole genome screening for copy number differences between the test and reference. It used metaphase chromosomes with a limited resolution of 5 to $10 \mathrm{Mb}^{16}$.

The next development was microarray or array $\mathrm{CGH}$ (aCGH). It is similar to CGH in that two "differentially" labeled specimens are hybridized together, using a variety of different clones. In contrast to $\mathrm{CGH}$, aCGH is not done in metaphase chromosomes but with DNA on a glass slide ${ }^{17,18}$. This allowed for the slides to be scanned and analyzed by software which detects the different fluorescent intensities or cytogenomic copy number variation $(\mathrm{CNV})$ between the patient and reference DNA.

The advantages of this technique are multiple. First, it allows for whole genome screening at resolution of $50 \mathrm{~kb}-1 \mathrm{Mb}$ (can be as small as $\sim 10 \mathrm{~kb}$ ) depending upon probe density on the array ${ }^{19}$. Second, aCGH can detect copy number variation in subtelomeric regions ${ }^{20}$. Third, recent development of aCGH with SNP (single nucleotide polymorphism) capacity can detect not only deletion, duplication and amplification but also uniparental disomy (UPD) ${ }^{21,22}$. Uniparental disomy of a whole chromosome or a segment of a chromosome has been associated with GDD and other phenotypes in many cases ${ }^{21,22}$. Finally, aCGH has almost $100 \%$ concordance with G-banding ${ }^{19}$ and/or FISH $^{23}$ in detecting clinically significant genomic imbalances.

By the early 2000's, aCGH had been verified as a tool to identify copy number differences. It was originally used in tumor studies and has since been a method of providing etiological diagnosis for patients with developmental delay and other clinical features. Etiological duplications or deletions have been found in $\sim 17 \%$ of individuals with undiagnosed GDD and/or other clinical phenotypes ${ }^{23-34}$. This detection rate proves aCGH to be much more sensitive than routine cytogenetic methods.

Furthermore, in most studies, patients have already been investigated, with karyotype, FISH, and/or neuroimaging. All diagnostic rates were in excess of $1 \%$, which is the diagnostic threshold stated by the American Academy of Neurology and the Child Neurology Society ${ }^{31}$ in evaluating a diagnostic test for developmental delay. Array $\mathrm{CGH}(\mathrm{aCGH})$, therefore, is an improvement over previous diagnostic techniques ${ }^{27,35}$ in undiagnosed developmental delay.

\section{Cost Effectiveness of aCGH in Clinical Practice}

Array $\mathrm{CGH}$ as an effective diagnostic tool in GDD has entered clinical practice in recent years. Positive aCGH may need further molecular cytogenetics tests on parents. With this extra testing, some have questioned its cost effectiveness. Array $\mathrm{CGH}$ in Ontario can cost up to 750 Canadian dollars for one analysis. Newman et al. reported no significant cost differences between routine cytogenetics and $\mathrm{aCGH}^{36}$. They concluded that aCGH in appropriately selected patients would have "minimal economic implications". More recently, Trakadis and Shevell analyzed the cost effectiveness of aCGH as a first line test versus initial karyotype and other diagnostics ${ }^{37}$. They found that the cost of aCGH was much lower at their university hospital network compared to private enterprise. With this lower cost, aCGH was in fact less expensive than the previous diagnostic route. They concluded that $\mathrm{aCGH}$ as a first line test is costeffective. A similar recommendation was made by Miller et al as they stated that aCGH is already less expensive than $\mathrm{G}$ banding karyotype followed up with a "customized" FISH test and aCGH is higher yield ${ }^{38}$. As well, the reduction in follow up visits following diagnosis with aCGH provides further savings.

The issue then becomes who constitutes an appropriate patient for aCGH testing. As aCGH is the highest yield test for developmental delay without etiological diagnosis, both the American College of Medical Genetics and Genomics (ACMG) and the Canadian College of Medical Geneticists (CCMG) have published recommendations regarding use of $\mathrm{aCGH}^{39}$. Array $\mathrm{CGH}$ is recommended as a first line investigation in patients meeting one of three criteria: multiple anomalies not specific to a known syndrome, patients with apparently non-syndromic developmental delay, or autism spectrum disorders. They also recommended performing a karyotype first if a common syndrome is suspected (Trisomy 21 or 18, sex chromosome aneuploidy). New directions for aCGH are also emerging in the field of prenatal diagnosis. Recent recommendations on this practice have been published by the CCMG and the Society of Obstetricians and Gynaecologists of Canada (SOGC) $)^{40}$.

With this new technology, there have been recommendations published as to when a medical genetics referral is necessary. Following aCGH, a referral is indicated for clinical evaluation and counseling ${ }^{39}$. Genetics referral is also indicated, as per ACMG guidelines in adults with a recognized genetic disorder or pediatric patients with congenital anomalies, failure to thrive, abnormal brain MRI findings, a known metabolic or chromosomal condition, or born to a parent with a known chromosomal abnormality, among others ${ }^{41}$.

\section{Limitations and challenges of aCGH}

Commercially available aCGH platforms generally cannot identify balanced translocations or inversions. Array CGH may miss mosaicism, depending upon the level of the mosaic cell line and the size and nature of the cytogenomic segments (e.g. small marker consisting mainly of centromeric repeats $)^{42,43}$. Interpretation of the clinical significance of some aCGH findings can be challenging, especially for variants of undetermined significance (VUS). Genome wide studies have found large scale copy CNV throughout the genome and the frequent occurrence of presumably benign CNVs in normal people ${ }^{44,45}$. The challenge with aCGH is to determine whether a positive test is related to the clinical phenotype ${ }^{29,31}$. A positive aCGH finding may necessitate confirmation by FISH or other DNA analyses of the patient as well as the parents ${ }^{39,46}$. The follow-up investigations can determine if the copy number change is de 
novo or inherited. If the parents test positive for the same copy number change and are unaffected, the change may be interpreted non-contributory. If the parents test negative and the copy number change is reported in multiple cases of GDD, it may be interpreted to be pathogenic or likely pathogenic. It should be pointed out that clinical interpretation of aCGH findings should take into consideration many factors, including gene content, size of the genomic interval, clinical history, and expressivity and penetrance of the inherited genetic changes.

The discovery of VUS may also cause anxiety to the family of the patient. There are various cytogenomic databases now available, including the University of California Santa Cruz (UCSC) Genome Browser, International Standard of Cytogenomic Array (ISCA) Consortium Database, Database of Genomic Variants (DGV), European Cytogeneticists Association Register of Unbalanced Chromosome Aberrations (EUCARUCA) and Database of Chromosomal Imbalance and Phenotype in Humans using Ensembl Resources (DECIPHER) $)^{16,47}$. These databases have been instrumental in interpretation of VUS and have helped improve aCGH as a clinical tool.

\section{aCGH and its Effect on Clinical Management}

An important aspect of any clinical test is its impact on patient management. As aCGH increases diagnostic rates, there are improvements in clinical management which are related to the inherent benefits in having a diagnosis. Saam et $\mathrm{al}^{48}$ studied how aCGH changed management in a group of GDD patients with diagnostic copy number change detected by aCGH. Of their original population, $70.8 \%$ had some changes in management due to aCGH. Of those who had no change in management upon receiving an etiological diagnosis, the majority of families still felt "relieved" by the information. They concluded that with diagnosis, aCGH was able to clarify recurrence risk, increase access to resources, and guide future referrals.

There are several other positive impacts of aCGH on clinical practice. With the sensitivity of the technology, many novel deletion and duplication syndromes have been established. Furthermore, for previously described syndromes, aCGH can expand our knowledge of the phenotypic variability that exists ${ }^{30}$. Finally, diagnosis can also provide families with a sense of control $^{49}$ and relief ${ }^{49}$, as etiologic diagnosis can be a long and drawn out process.

Array CGH has also been demonstrated to be useful in other clinical scenarios related to neurology. A recent study found aCGH to provide etiological diagnosis in $28 \%(7 / 25)$ of previously undiagnosed children with movement disorders ${ }^{50}$. All of the positive cases had some level of learning disability. This suggests that aCGH also may play a role in providing etiological diagnosis in neurological clinical scenarios where developmental delay may only be part of the presentation.

\section{Illustrative Case}

This patient was originally evaluated by the genetics department at 1 and 13 years-of-age for global developmental delay. He was reevaluated at 31-years-of-age for global developmental delay, dysmorphic features, and concern surrounding the heritability of his condition. His parents are nonconsanguineous of Scottish ethnicity. His mother was a 30year-old gravida 1 and had amniocentesis during her pregnancy. Cytogenetic analysis was initially performed by low-resolution Q-banding in 1980, which was interpreted as a normal male karyotype $(46, \mathrm{XY})$. The proband had a birth weight of $3.280 \mathrm{~kg}$, head circumference of $37 \mathrm{~cm}$ (greater than $97 \mathrm{th}$ percentile) and hypotonia was noted. At one year, his development was delayed and communicating hydrocephalus was found on cranial CT scan. This was treated with a ventricular peritoneal shunt and his development improved. A possible diagnosis of Prader-Willi syndrome was suspected at birth but was deemed unlikely due to his hydrocephalus, frontal bossing, and normal weight. His parents later had another male child born without dysmorphic features or developmental delay.

On examination, his height was $171.3 \mathrm{~cm}$ (25th centile) and he weighed $87.7 \mathrm{~kg}$ (75th-90th centile). He was non-verbal, and uses gestures for communication, in keeping with his documented intellectual disability. With receptive language, he understood verbal commands. His gait was unsteady and he was mostly confined to a wheel chair. On craniofacial exam, he had an enlarged skull, short palpebral fissures $(2.5 \mathrm{~cm})$, high arched palate and low set, posteriorly rotated ears (Figure 1). His teeth were short. His hands were small and his fifth digit and third toe were were shortened bilaterally. His lower limb reflexes were brisk.

Array $\mathrm{CGH}$ was performed as the first line investigation as per our current guidelines, using DNA extracted from the blood and analyzed utilizing an Agilent oligonuclietide array (180K) and Bluegnome software. The aCGH analysis identified a 20.8

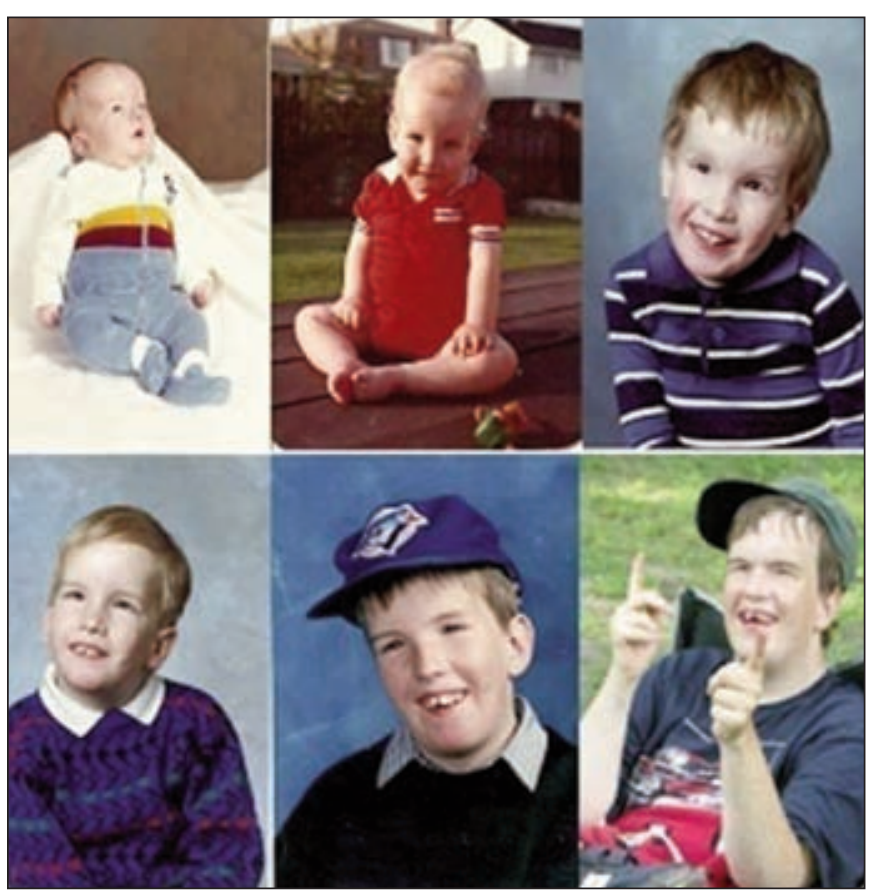

Figure 1: Views of the propositus at the age of (from top left): 4 months, 2 years, 5 years, 8 years, 12 years and 29 years. 


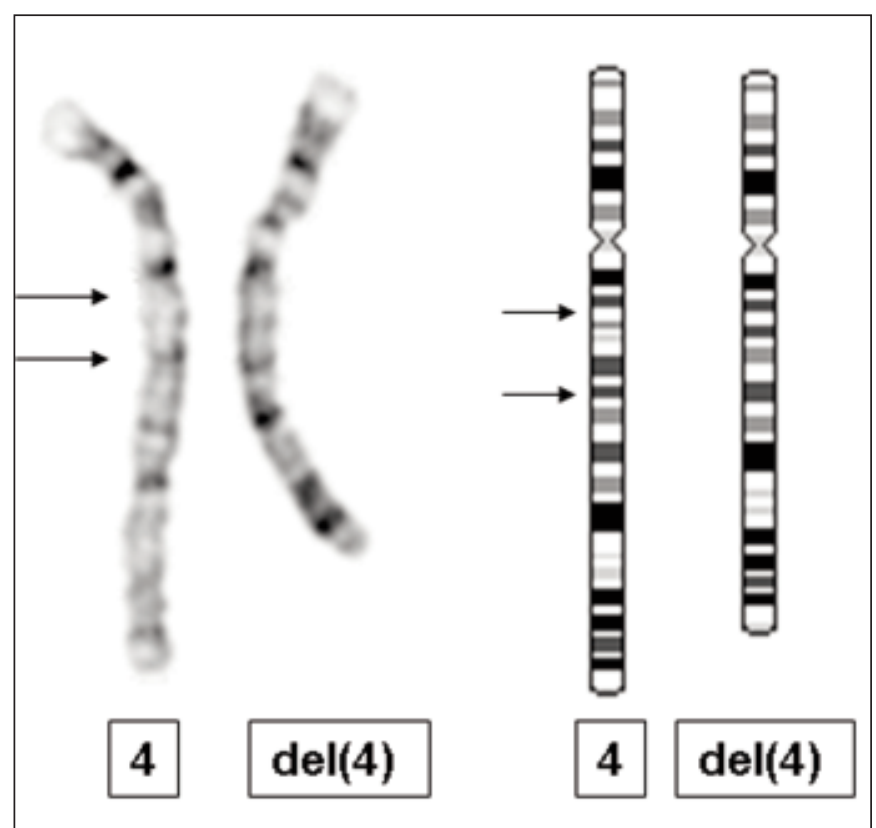

Figure 2: G-banding showing a normal chromosome 4 (left) and an abnormal chromosome 4 with a deletion of 4 q21.1q22.3 (arrows). This result confirms aCGH finding.

$\mathrm{Mb}$ deletion in chromosome region 4q21.1q22.3 (chr4: $77,796,761-98,589,579[\mathrm{hg} 18])$. The $4 \mathrm{q}$ deletion involves 65 OMIM genes including 9 OMIM morbid genes (http://genome.ucsc.edu). In addition, the aCGH detected two smalller duplications at Xp22.33: $0.724 \mathrm{Mb}$ (chrX:387,409$1,112,282$ [hg18]) and $0.592 \mathrm{Mb}$ (chrX:1,434,992-2,026,644 [hg18]). The $0.724 \mathrm{Mb}$ duplication involves an OMIM morbid gene (SHOX); its duplication has been reported in patients with developmental delay, congenital anomalies and Asperger syndrome $^{51,52}$. However, this duplication may be inherited from an unaffacted father and the clinical significance of this duplication is uncertain. The $0.592 \mathrm{Mb}$ duplication has not been associated with any syndrome or disease and its clinical significance remains uncertain due to lack of publications on the duplication of this interval. Given the large 4q21 deletion, neither duplication was considered likely to significantly contribute to our patient's presentation. The $4 \mathrm{q}$ deletion was confirmed by G-banding analysis (Figure 2) and interpreted as de novo since the parents had a normal karyotype.

At least 15 patients have been reported with deletions involving the $4 \mathrm{q} 21$ region $^{53-57}$. $4 \mathrm{q} 21$ deletion has been summarized as a syndrome of four features ${ }^{53}$ : severe mental retardation, severely delayed or absent speech, dysmorphic facial features, and short stature, and is an example of a novel syndrome that has been documented due to aCGH. The deletion in the present case is the largest among the deletions in this $4 \mathrm{q}$ region reported.

Efforts have been made to identify the genes responsible for the phenotype seen in $4 \mathrm{q} 21$ deletion syndrome. A region of shared overlap among previous cases was found to include two genes: PRKG2 and RASGEF1B ${ }^{53}$. PRKG2 encodes a protein kinase that is expressed in cartilage and other tissues. Mutations in PRKG2 are associated with a natural dwarf rat phenotype ${ }^{58}$ and its deletion may result in short stature. RASGEF1B encodes a guanine nucleotide exchange factor for RAS proteins expressed in the central nervous system $(\mathrm{CNS})^{53}$. These genes may be responsible for the neurodevelopmental phenotype.

The patient's family decided to once again search for a diagnosis after giving up almost 20 years prior as the patient's unaffected sibling was considering starting a family. The resulting diagnosis provided closure as they had been part of a diagnostic odyssey for over 30 years. With the provision of an etiology, the family has been able to access internet resources and additional information about 4q21 deletion syndrome.

\section{Conclusion}

For patients with developmental delay, approximately only half are provided with etiological diagnosis. Array CGH can help significantly improve the diagnostic rate and therefore should be considered a first line investigation in developmental delay. It has also been shown to be useful in other clinical scenarios related to neurology where developmental delay is only part of the presenting phenotype. Pre-test genetic counseling is needed to discuss benefits as well as limitations of the aCGH testing. The expectations of the family need to be assessed and the clinician must ensure that they are in keeping with the expected benefits of a diagnosis. Array CGH has been proven as a valuable first line tool for neurologists as well as geneticists in investigation of developmental delay.

\section{ACKNOWLEDGEMENTS}

We are grateful to the patient and his family for their cooperation.

FC drafted the illustrative case and review of array CGH and its implications for neurologists with the help from CP. JX contributed cytogenetic and array $\mathrm{CGH}$ analyses of the illustrative case. JJ and all others edited the manuscript.

Electronic database information. URL used in preparation of this article: Online Mendelian Inheritance in Man, OMIM (TM). Center for Medical Genetics, Johns Hopkins University (Baltimore, MD) and National Center for Biotechnology Information, National Library of Medicine (Bethesda, MD), 1999. World Wide Web URL: http://www.ncbi.nlm.nih.gov/ omim.

The aCGH analysis was done in Dr. Marsha Speevak's laboratory at Credit Valley Hospital University of Toronto, Toronto, Ontario, Canada.

\section{REFERENCES}

1. Curry CJ, Stevenson RE, Aughton D, et al. Evaluation of mental retardation: Recommendations of a consensus conference: American college of medical genetics. Am J Med Genet. 1997 Nov 12;72(4):468-77.

2. Battaglia A, Carey JC. Diagnostic evaluation of developmental delay/mental retardation: An overview. Am J Med Genet C Semin Med Genet. 2003 Feb 15;117C(1):3-14.

3. van Karnebeek CD, Jansweijer MC, Leenders AG, Offringa M, Hennekam RC. Diagnostic investigations in individuals with mental retardation: A systematic literature review of their usefulness. Eur J Hum Genet. 2005 Jan;13(1):6-25. 
4. White BJ, Ayad M, Fraser A, et al. A 6-year experience demonstrates the utility of screening for both cytogenetic and FMR-1 abnormalities in patients with mental retardation. Genet Test. 1999;3(3):291-6.

5. Graham SM, Selikowitz M. Chromosome testing in children with developmental delay in whom the aetiology is not evident clinically. J Paediatr Child Health. 1993 Oct;29(5):360-2.

6. Volcke P, Dereymaeker AM, Fryns JP, van den Berghe H. On the nosology of moderate mental retardation with special attention to X-linked mental retardation. A diagnostic genetic survey of 274 institutionalized moderately mentally retarded men. Genet Couns. 1990;1(1):47-56.

7. Lamont MA, Dennis NR, Seabright M. Chromosome abnormalities in pupils attending ESN/M schools. Arch Dis Child. 1986 Mar; 61(3):223-6.

8. Shevell MI, Majnemer A, Rosenbaum P, Abrahamowicz M. Etiologic yield of subspecialists' evaluation of young children with global developmental delay. J Pediatr. 2000 May;136(5): 593-8.

9. Battaglia A, Bianchini E, Carey JC. Diagnostic yield of the comprehensive assessment of developmental delay/mental retardation in an institute of child neuropsychiatry. Am J Med Genet. 1999 Jan 1;82(1):60-6.

10. Shevell M, Ashwal S, Donley D, et al. Practice parameter: Evaluation of the child with global developmental delay: Report of the quality standards subcommittee of the American Academy of Neurology and the practice committee of the Child Neurology Society. Neurology. 2003 Feb 11;60(3):367-80.

11. Sanchez O, Escobar JI, Yunis JJ. A simple G-banding technique. Lancet. 1973 Aug 4;2(7823):269.

12. Flint J, Wilkie AO, Buckle VJ, Winter RM, Holland AJ, McDermid HE. The detection of subtelomeric chromosomal rearrangements in idiopathic mental retardation. Nat Genet. 1995 Feb;9(2): $132-40$.

13. de Vries BB, White SM, Knight SJ, et al. Clinical studies on submicroscopic subtelomeric rearrangements: A checklist. J Med Genet. 2001 Mar;38(3):145-50.

14. Shaffer LG, Bejjani BA. Medical applications of array CGH and the transformation of clinical cytogenetics. Cytogenet Genome Res. 2006;115(3-4):303-9.

15. Kallioniemi A, Kallioniemi OP, Sudar D, et al. Comparative genomic hybridization for molecular cytogenetic analysis of solid tumors. Science. 1992 Oct 30;258(5083):818-21.

16. Edelmann L, Hirschhorn K. Clinical utility of array CGH for the detection of chromosomal imbalances associated with mental retardation and multiple congenital anomalies. Ann N Y Acad Sci. 2009 Jan;1151:157-66.

17. Solinas-Toldo S, Lampel S, Stilgenbauer S, et al. Matrix-based comparative genomic hybridization: Biochips to screen for genomic imbalances. Genes Chromosomes Cancer. 1997 Dec;20 (4):399-407.

18. Pinkel D, Segraves R, Sudar D, et al. High resolution analysis of DNA copy number variation using comparative genomic hybridization to microarrays. Nat Genet. 1998 Oct;20(2):207-11.

19. Baldwin EL, Lee JY, Blake DM, et al. Enhanced detection of clinically relevant genomic imbalances using a targeted plus whole genome oligonucleotide microarray. Genet Med. 2008 Jun;10(6):415-29.

20. Speicher MR, Carter NP. The new cytogenetics: Blurring the boundaries with molecular biology. Nat Rev Genet. 2005 Oct;6 (10):782-92.

21. Kearney HM, Kearney JB, Conlin LK. Diagnostic implications of excessive homozygosity detected by SNP-based microarrays: Consanguinity, uniparental disomy, and recessive single-gene mutations. Clin Lab Med. 2011 Dec;31(4):595,613, ix.

22. Papenhausen P, Schwartz S, Risheg H, et al. UPD detection using homozygosity profiling with a SNP genotyping microarray. Am J Med Genet A. 2011 Apr;155A(4):757-68.

23. Toruner GA, Streck DL, Schwalb MN, Dermody JJ. An oligonucleotide based array-CGH system for detection of genome wide copy number changes including subtelomeric regions for genetic evaluation of mental retardation. Am J Med Genet A. 2007 Apr 15;143A(8):824-9.
24. Vissers LE, de Vries BB, Osoegawa K, et al. Array-based comparative genomic hybridization for the genomewide detection of submicroscopic chromosomal abnormalities. Am J Hum Genet. 2003 Dec;73(6):1261-70.

25. Shaw-Smith C, Redon R, Rickman L, et al. Microarray based comparative genomic hybridisation (array-CGH) detects submicroscopic chromosomal deletions and duplications in patients with learning disability/mental retardation and dysmorphic features. J Med Genet. 2004 Apr;41(4):241-8.

26. Schoumans J, Ruivenkamp C, Holmberg E, Kyllerman M, Anderlid BM, Nordenskjold M. Detection of chromosomal imbalances in children with idiopathic mental retardation by array based comparative genomic hybridisation (array-CGH). J Med Genet. 2005 Sep;42(9):699-705.

27. de Vries BB, Pfundt R, Leisink M, et al. Diagnostic genome profiling in mental retardation. Am J Hum Genet. 2005 Oct;77 (4):606-16.

28. Menten B, Maas N, Thienpont B, et al. Emerging patterns of cryptic chromosomal imbalance in patients with idiopathic mental retardation and multiple congenital anomalies: A new series of 140 patients and review of published reports. J Med Genet. 2006 Aug;43(8):625-33.

29. Rosenberg C, Knijnenburg J, Bakker E, et al. Array-CGH detection of micro rearrangements in mentally retarded individuals: Clinical significance of imbalances present both in affected children and normal parents. J Med Genet. 2006 Feb;43(2): 180-6.

30. Krepischi-Santos AC, Vianna-Morgante AM, Jehee FS, et al. Whole-genome array-CGH screening in undiagnosed syndromic patients: Old syndromes revisited and new alterations. Cytogenet Genome Res. 2006;115(3-4):254-61.

31. Shevell MI, Bejjani BA, Srour M, Rorem EA, Hall N, Shaffer LG. Array comparative genomic hybridization in global developmental delay. Am J Med Genet B Neuropsychiatr Genet. 2008 Oct 5;147B(7):1101-8.

32. Pickering DL, Eudy JD, Olney AH, et al. Array-based comparative genomic hybridization analysis of 1176 consecutive clinical genetics investigations. Genet Med. 2008 Apr;10(4):262-6.

33. Manolakos E, Vetro A, Kefalas K, et al. The use of array-CGH in a cohort of Greek children with developmental delay. Mol Cytogenet. 2010 Nov 9:3:22.

34. Shoukier M, Klein N, Auber B, et al. Array CGH in patients with developmental delay or intellectual disability: Are there phenotypic clues to pathogenic copy number variants? Clin Genet. 2013 Jan;83(1):53-65

35. Bejjani BA, Shaffer LG. Clinical utility of contemporary molecular cytogenetics. Annu Rev Genomics Hum Genet. 2008;9:71-86.

36. Newman WG, Hamilton S, Ayres J, et al. Array comparative genomic hybridization for diagnosis of developmental delay: An exploratory cost-consequences analysis. Clin Genet. 2007 Mar; 71(3):254-9.

37. Trakadis Y, Shevell M. Microarray as a first genetic test in global developmental delay: A cost-effectiveness analysis. Dev Med Child Neurol. 2011 Nov;53(11):994-9.

38. Miller DT, Adam MP, Aradhya S, et al. Consensus statement: Chromosomal microarray is a first-tier clinical diagnostic test for individuals with developmental disabilities or congenital anomalies. Am J Hum Genet. 2010 May 14;86(5):749-64.

39. Manning M, Hudgins L, Professional Practice and Guidelines Committee. Array-based technology and recommendations for utilization in medical genetics practice for detection of chromosomal abnormalities. Genet Med. 2010 Nov;12(11): $742-5$.

40. Duncan A, Langlois S, SOGC Genetics Committee, CCMG Prenatal Diagnosis Committee. Use of array genomic hybridization technology in prenatal diagnosis in Canada. $\mathrm{J}$ Obstet Gynaecol Can. 2011 Dec;33(12):1256-9.

41. Pletcher BA, Toriello HV, Noblin SJ, et al. Indications for genetic referral: A guide for healthcare providers. Genet Med. 2007 Jun; 9(6):385-9.

42. Youssoufian H, Pyeritz RE. Mechanisms and consequences of somatic mosaicism in humans. Nat Rev Genet. 2002 Oct;3(10): $748-58$ 
43. Ballif BC, Rorem EA, Sundin K, et al. Detection of low-level mosaicism by array $\mathrm{CGH}$ in routine diagnostic specimens. Am J Med Genet A. 2006 Dec 15;140(24):2757-67.

44. Sebat J, Lakshmi B, Troge J, et al. Large-scale copy number polymorphism in the human genome. Science. 2004 Jul 23;305 (5683):525-8.

45. Iafrate AJ, Feuk L, Rivera MN, et al. Detection of large-scale variation in the human genome. Nat Genet. 2004 Sep;36(9): 949-51.

46. Bejjani BA, Saleki R, Ballif BC, et al. Use of targeted array-based $\mathrm{CGH}$ for the clinical diagnosis of chromosomal imbalance: Is less more? Am J Med Genet A. 2005 Apr 30;134(3):259-67.

47. Shinawi M, Cheung SW. The array CGH and its clinical applications. Drug Discov Today. 2008 Sep;13(17-18):760-70.

48. Saam J, Gudgeon J, Aston E, Brothman AR. How physicians use array comparative genomic hybridization results to guide patient management in children with developmental delay. Genet Med. 2008 Mar;10(3):181-6.

49. Moeschler JB, Shevell M, American Academy of Pediatrics Committee on Genetics. Clinical genetic evaluation of the child with mental retardation or developmental delays. Pediatrics. 2006 Jun;117(6):2304-16.

50. Dale RC, Grattan-Smith P, Nicholson M, Peters GB. Microdeletions detected using chromosome microarray in children with suspected genetic movement disorders: A singlecentre study. Dev Med Child Neurol. 2012 Jul;54(7):618-23.

51. Thomas NS, Harvey JF, Bunyan DJ, et al. Clinical and molecular characterization of duplications encompassing the human SHOX gene reveal a variable effect on stature. Am J Med Genet A. 2009 Jul;149A(7):1407-14.
52. Roos L, Brondum Nielsen K, Tumer Z. A duplication encompassing the SHOX gene and the downstream evolutionarily conserved sequences. Am J Med Genet A. 2009 Dec;149A(12):2900-1.

53. Bonnet C, Andrieux J, Beri-Dexheimer M, et al. Microdeletion at chromosome 4q21 defines a new emerging syndrome with marked growth restriction, mental retardation and absent or severely delayed speech. J Med Genet. 2010 Jun;47(6):377-84.

54. Dukes-Rimsky L, Guzauskas GF, Holden KR, et al. Microdeletion at $4 \mathrm{q} 21.3$ is associated with intellectual disability, dysmorphic facies, hypotonia, and short stature. Am J Med Genet A. 2011 Sep;155A(9):2146-53

55. Friedman JM, Baross A, Delaney AD, et al. Oligonucleotide microarray analysis of genomic imbalance in children with mental retardation. Am J Hum Genet. 2006 Sep;79(3):500-13.

56. Dobyns WB, Mirzaa G, Christian SL, et al. Consistent chromosome abnormalities identify novel polymicrogyria loci in $1 \mathrm{p} 36.3$, 2p16.1-p23.1, 4q21.21-q22.1, 6q26-q27, and 21q2. Am J Med Genet A. 2008 Jul 1;146A(13):1637-54.

57. Harada N, Nagai T, Shimokawa O, Niikawa N, Matsumoto N. A 4q21-q22 deletion in a girl with severe growth retardation. Clin Genet. 2002 Mar;61(3):226-8.

58. Chikuda H, Kugimiya F, Hoshi K, et al. Cyclic GMP-dependent protein kinase II is a molecular switch from proliferation to hypertrophic differentiation of chondrocytes. Genes Dev. 2004 Oct 1;18(19):2418-29. 